\title{
Hepatitis C and Why the Treatment is Needed Now? The Summary Report From the Cross-Border Symposium of the 5th Tehran Hepatitis Congress May 2013
}

\author{
Nasser Ebrahimi Daryani ${ }^{1}$, Seyed Moayed Alavian ${ }^{2,3,}$, Mohammad Hossein Somi ${ }^{4}$, Moham- \\ mad Torabi-Nami ${ }^{5}$ \\ ${ }_{2}^{1}$ Department of Gastroenterology and Hepatology, Tehran University of Medical Sciences, Tehran, IR Iran \\ ${ }_{2}^{2}$ Baqiyatallah Research Center for Gastroenterology and Liver Disease, Baqiyatallah University of Medical Sciences, Tehran, IR Iran \\ ${ }_{4}^{3}$ Middle East Liver Disease Center(MELD), Tehran, IR Iran \\ ${ }_{5}^{4}$ Research Center for Gastroenterology and Liver Disease, Tabriz University of Medical Sciences, Tabriz, IR Iran \\ ${ }^{5}$ School of Advanced Medical Science and Technologies, Shiraz University of Medical Sciences, Shiraz, IR Iran \\ *Corresponding author: Seyed Moayed Alavian, Baqiyatallah University of Medical Sciences, Tehran, IR Iran. Tel:+98-2188945187, Fax:+98-2188945186, E-mail: editor@hepatmon.com.
}

Received: November 9, 2013; Accepted: November 12, 2013

\begin{abstract}
The cross-border symposium on hepatitis C, entitled "why treating now?" was held on 15th May 2013 during the 5th International Tehran Hepatitis Congress. The present report summarizing communicated insights during this symposium is intended to help health care providers to make well-informed decisions when treating patients with chronic hepatitis C (CHC). Since today's evolving science of hepatitis C management has introduced new treatment options, one should be well-versed about the potential benefits as well as untoward effects or practical challenges when using these regimens. In addition to outline HCV treatment advances, this symposium focused on the central question that why eligible patients with hepatitis $C$ who may mostly benefit from the currently available protease inhibitors, should be treated now rather than be waited for the future therapies. Moreover, an overview of long term local experience with protease inhibitors in our challenging hepatitis $\mathrm{C}$ patients was presented during this interactive symposium.
\end{abstract}

Keywords: Hepatitis C; Protease Inhibitors; Management; Iran

\section{Introduction}

The therapeutic strategies for chronic hepatitis $\mathrm{C}(\mathrm{CHC})$ has notably evolved over the past two decades. Treatment protocol began with interferon alpha (IFN- $\alpha$ ) monotherapy in 1993, thereafter it moved on adding ribavirin (RBV) to IFN- $\alpha$ in 1998, and finally pegylated IFN- $\alpha$ (PegIFN- $\alpha$ ) was emerged in 2000. The combination therapy with PegIFN- $\alpha$ and RBV became the standard of care since 2001(1, 2). Currently, despite the introduction of directacting antivirals (protease inhibitors or PIs) including Boceprevir and Telaprevir since 2011, and the ongoing research for new HCV therapies, PegIFN- $\alpha$ plus RBV have remained the backbone of $\operatorname{HCV}$ treatment $(2,3)$.

Our local experience with PegIFN- $\alpha$ plus RBV combination therapy over the past years has shown that 50 to $70 \%$ of the patients achieve the sustained virological response (SVR) depending on their genotype (whether 1a or non1a), and other predictive variables (4-6). Nevertheless, given the lack of expected response or failed prior therapy in distinct category of patients (i.e. either naïve or treatment-experienced genotype $1 \mathrm{HCV}$-infected patients), the
PI (Boceprevir or Telaprevir)-included triple therapy has become indicated (7-10).

The most recent international guidelines for the diagnosis and management of hepatitis $C(11,12)$, have recommended the PI-based triple therapy for patients with genotype 1, regardless of their prior treatment response. However, considering the cost and availability issue of such treatment regimens, local recommendations would assist clinicians with their decision-making in this regard. The recommendations laid down by the experts panel during the scientific leaders' meeting, July 2011, Tehran (13), re-emphasized the significance of evidencebased decisions for using any new HCV therapy regimen in Iran; whereby, cost-benefit analysis should be carefully considered before decision making.

Given this, a clear understanding on these regimens' implications, benefits, untoward effects or practical challenges are needed. This symposium tried to highlight: (1) why timely treatment with the currently available PI-included triple therapy is needed for a distinct category of patients, and waiting for future therapies is normally not recommended, (2) what practical considerations must

Implication for health policy/practice/research/medical education:

The manuscript can help the clinicians how to manage the HCV infected patients and we recommend reading it to all internists, infectious specialists, hepatologist and family physicians.

Copyright (C) 2013, Kowsar Corp.; Published by Kowsar Corp. This is an open-access article distributed under the terms of the Creative Commons Attribution License, which permits unrestricted use, distribution, and reproduction in any medium, provided the original work is properly cited. 
be noted when applying these regimens, and (3) where we stand regarding our local experience with PI-included triple therapy for GT1 HCV-infected patients.

\subsection{Today's Landscape of Hepatitis C Treatment}

When navigating the new landscape of hepatitis $C$ treatment with the currently approved direct acting antivirals (DAAs), some questions emerge. Some fundamental issues which need to be clarified include:(1) which patients should be treated with these regimens? (2) what preparations are mandated before initiating the therapy? (3) how should we manage possible adverse events (AEs) ?, and (4) when the treatment should be stopped?

According to the guidelines, patients with at least 18 years of age, having detectable genotype (GT) 1 HCV RNA in the serum, with a compensated liver disease, and liver biopsy showing a significant fibrosis (bridging fibrosis or higher) resemble the portrayal of cases in whom timely initiation of PI-included HCV treatment is usually not debated $(11,12)$.

Before commencing the HCV treatment, some clinical, hematological, and biochemical indices should be evaluated, and the baseline proper status needs to be ascertained. The absence of evidence favoring hepatic encephalopathy or ascites, total serum bilirubin of less than 1.5 $\mathrm{gr} / \mathrm{dL}$, international normalized ratio (INR) of less than 1.5 , albumin $>3.4 \mathrm{gr} / \mathrm{dL}$, and the platelet count of at least $75000 / \mathrm{mm}^{3}$ are amongst the crucial baseline requirements to start HCV therapy with the new DAA (protease inhibitors)-included regimens. Some further essential hematological as well as biological indices include hemoglobin $(\mathrm{Hb})>13 \mathrm{gr} / \mathrm{dL}$ for men, and $>12 \mathrm{gr} / \mathrm{dL}$ for women, neutrophil count of more than 1500 cells $/ \mathrm{mm} 3$, and the serum creatinine level of less than $1.5 \mathrm{mg} / \mathrm{dL}$ (7,14-17).

Adding to the above, the two cardinal factors which motivate physicians to start HCV therapy with the newly available HCV treatment are patient's willingness to treatment, and to conform to the treatment requirements as well as lack of treatment contraindications.

The natural course of HCV infection leaves over $80 \%$ of the afflicted cases to become chronic, of which almost $20 \%$ end up with cirrhosis within 10-20 years since diagnosis. Cirrhosis in turn leads to possible progression to the end-stage liver disease, and hepatocellular carcinoma (HCC) with an incidence rate of $6 \%$ per year, and $4 \%$ per year, respectively. The rate of liver transplantation and death is 3-4\% per year when these complications develop (18). While decompensated cirrhosis is known to be a contraindication for triple therapy, compensated cirrhosis should not be excluded from such treatment regimens (19).

Given the potential post liver transplantation complications as well as the minimal $(<5 \%)$ five-year survival among patients with HCC, timely treatment of HCV to prevent disease progression into devastating liver dam- ages, and the terminal disease state is believed to be a "must do" $(2,12)$.

Treatment is meanwhile contraindicated in pregnant patients and those contemplating pregnancy or unwilling to assure contraception. Since interferon (either pegylated or non-pegylated) and ribavirin (RBV) are pregnancy category $\mathrm{X}$ and $\mathrm{C}$ respectively, and protease inhibitors (Boceprevir or Telaprevir) are to be only used in combination with PegIFN and RBV, PIs become contraindicated in pregnant patients and couples planning pregnancy. Other contraindications for PI-included triple therapy are severe and uncontrolled concurrent diseases such as hypertension, heart failure, coronary artery disease, chronic obstructive pulmonary disease, poorly controlled diabetes mellitus, and known hypersensitivity to any of the drugs used in the triple combination (20-25).

Regarding HCV treatment, further advancements are already underway which have promised combination therapies purporting even more pronounced efficacy and less adverse events, as well as interferon-free regimens $(26,27)$.

Given the above, an almost universal question for patients with genotype-1 related CHC is whether they should be treated now of wait for future therapies. In reply to this question, current practice guidelines have left a large group of patients and treating physicians to individually weigh the risks against benefits of initiating therapy vs. watchful waiting $(2,11)$. Meanwhile, clinical evidence has suggested that patients with intractable CHC-related symptoms such as fatigue and those with extra hepatic manifestations including cryoglobulinemia, renal disease, and dermatologic manifestations should be treated now regardless of their stage of liver disease (11). Due to the poorly defined high progression rate of $\mathrm{CHC}$, some other groups of patients are also recommended to be treated now. This subset of patients with initial high risk factors and faster progression of fibrosis include patients with infection after the age of 40 , male gender, excessive alcohol consumption, HBV or HIV coinfection, steatosis, and prolonged immunosuppressed state (2).

Even in those CHC patients whose liver biopsy shows limited portal fibrosis (i.e. METAVIR score of 1 and 2), careful decision about the time of therapy should be made as in many instances treating now is better if there is no major burden or contraindication $(11,18)$.

In addition, in patients with high fibrosis level and comorbidities, waiting for future therapies leads to a missed window of opportunity to successfully eradicate the virus using the currently available therapy. Apparently, eradicating the virus not only provides benefits to the patients, but also decreases the risk of viral transmission to the community (2).

In fact, while the nascent field of HCV therapy with its evolving science has offered promise for interferon-free regimens (27-29), many issues remain unknown including the time to approval, worldwide availability, cost bur- 
den, safety profiles, and most importantly their impact on viral resistance as well as the durability of virological response. Consequently, we need to ascertain to what extent "waiting" is safe for patients when replying to their question "shall I be treated now?"(2).

\section{Hepatitis C Treatment; A Changing Era}

The combination regimen of PegIFN plus RBV has resulted in the sustained virological response (SVR) rate of almost $80 \%$ in GT2 and 3, and 45\% in GT1. This regimen has remained the standard of care since 2001. Meanwhile, considering cellular and molecular pathways, which partly govern HCV replication and the response to IFN, in 2011, the direct acting antivirals (DAAs) as protease inhibitors (PIs) were added to PegIFN+RBV (R/R) regimen increasing the overall GT1 SVR rate up to $75 \%(7,14,30)$.

Since 2011, the international guidelines have put forward the PI-included triple therapy (i.e. Boceprevir or Telaprevir together with $\mathrm{P} / \mathrm{R}$ ) as the standard of care for GT1 HCV. These PIs directly interfere with the HCV polyprotein processing and viral protein function acting on a nonstructural (NS) serine protease known as NS3/4A (11, $12,30,31)$.

While we have recently started to experience the added value of the currently available PIs (Boceprevir and Telaprevir), there are some underway regimes expected to be available in coming years; however, their approval time is not clear yet. These molecules include Simeprevir, and Faldaprevir (to be added to P/R) for GT1 (28) as well as Sofosbuvir, (27) and Daclatasvir (32) for all genotypes. Sofosbuvir (as NS5B PI) is added to RBV and provides an IFNfree regimen for GT2 and 3 (27). The critical question of "why treatment with the currently available (Boceprevir or Telaprevir) PI-included therapy should be considered for many patients now, while for some others waiting for future therapies might possibly be considered" has been the focus of this report.

From the clinical point of view, factors predictive of a high likelihood of response to PI-based triple therapy are white race, low fibrosis level, rapid virological response (RVR), previous relapse following P/R therapy (vs. previous partial or null-response), and favorable IL28 CC genotype which is a marker of IFN responsiveness (33).

When determining HCV candidates for Boceprevir or Telaprevir, treating physicians should bear in mind the contraindications and precautions for using these agents in specific patients. In fact, all contraindications to $\mathrm{P} / \mathrm{R}$ apply to these agents. Some contraindications include end-stage decompensated liver disease, coinfection with HIV (there are ongoing studies for HIV coinfections for BOC and TLV) or HBV, pediatrics, organ transplantation, and coadministration with other drugs which are highly dependent on CYP3A for clearance or strongly induce this cytochrome $(24,25)$.

\subsection{Boceprevir-Included Triple Combination in $\mathrm{HCV}$ Treatment}

Boceprevir is always used in combination with $\mathrm{P} / \mathrm{R}$ to treat GT1 HCV. The triple combination comprises PegIFN $\alpha$ (2b: $1.5 \mu \mathrm{g} / \mathrm{kg} / \mathrm{wk}$ or $2 \mathrm{a}: 180 \mu \mathrm{g} / \mathrm{wk}$, subcutaneously) plus RBV (800-1400 mg/day) plus Boceprevir $200 \mathrm{mg}$ cap (800mg TID, every 7-9 hours with a light meal or snack). The treatment schedule includes 4 weeks of $\mathrm{P} / \mathrm{R}$ as the lead-in phase followed by Boceprevir-included triple therapy for which the response-guided therapy (RGT) applies for naive patients (Figure 1) $(7,8,24)$.

Figure 1. Boceprevir-Included Triple Combination and the Response Guided Therapy (RGT)

\begin{tabular}{l|l|l|}
\hline & \\
\hline
\end{tabular}

The duration of BOC containing triple therapy depends on the initial treatment response at week 8 of therapy (week 4 of triple combination), and the virological response documented at week 24 for naive patients. As demonstrated in the diagram all treatment schedules possess a 4 week $\mathrm{P} / \mathrm{R}$ (lead-in) treatment phase, and boceprevir is added at week 4 . In treatment naive early responders (negative HCV RNA at week 8), the schedule would be $4 \mathrm{w}(\mathrm{P} / \mathrm{R})+24 \mathrm{w}(\mathrm{B} / \mathrm{P} / \mathrm{R})$. In treatment experienced patients and treatment naive late responders (HCV RNA detectable at week 8 and undetectable at week 24), also in nonresponders with negative results for HCV RNA at week 8 , the treatment would include $4 \mathrm{w}(\mathrm{P} / \mathrm{R})+32 \mathrm{w}(\mathrm{B} / \mathrm{P} / \mathrm{R})+12 \mathrm{w}$ $(\mathrm{P} / \mathrm{R})$. Finally, in null-responders and patients with cirrhosis regardless of on-treatment or prior response, the schedule is $4 \mathrm{w}(\mathrm{P} / \mathrm{R})+44 \mathrm{w}(\mathrm{B} / \mathrm{P} / \mathrm{R})$. Boc: boceprevir, $\mathrm{P} / \mathrm{R}$ : Pegylated Interferon $\alpha /$ Ribavirin.

\subsection{Telaprevir-Included Triple Combination in $\mathrm{HCV}$ Treatment}

Telaprevir should be administered in combination with $\mathrm{P} / \mathrm{R}$ beginning on the first day. This triple combination is given for a fixed duration of 12 weeks after which the whole treatment duration with $\mathrm{P} / \mathrm{R}$ (24 vs. 48 weeks) is determined based on the RVR achievement (Figure 2).

\begin{tabular}{l|l}
\hline Figure 2. Telaprevir-Included Triple Therapy for GT1 HCV \\
\hline Treatment naïve with RVR. Prior relapse with RVR \\
All patient without RVR, Prior partial and null-response, All patients with cirrhosis \\
WO W4 W12
\end{tabular}

The duration of Telaprevir-included triple therapy is 12 weeks, and response-guided therapy (RGT) does not apply to this fixed treatment phase. However, the whole treatment duration ( 24 vs. 48 weeks) is determined by the achievement of the rapid virological response (RVR) which corresponds to un-detectability of HCV RNA 4 weeks after the initiation of Telaprevir-included triple therapy. TLV: Telaprevir, P/R: Pegylated Interferon $\alpha /$ Ribavirin.

Each dose of Telaprevir is $750 \mathrm{mg}$ (two 375mg tablets) 
which should be taken with approximately $20 \mathrm{~g}$ fat-containing food. The triple combination comprises PegIFN $\alpha$ (2b: $1.5 \mu \mathrm{g} / \mathrm{kg} /$ wk or $2 \mathrm{a}: 180 \mu \mathrm{g} / \mathrm{wk}$, subcutaneously) plus RBV (800-1400 mg/day) plus Telaprevir $375 \mathrm{mg}$ tab (750 mg TID, every 7-9 hours) ( 25 ). Depending on the HCV RNA level or its detectability at distinct milestones upon treatment with Boceprevir- or Telaprevir-included tripe therapy, the therapy is perceived non-efficacious, and hence should be stopped. The futility (stopping) rules for Boceprevir and Telaprevir slightly vary. This has been summarized in Figure 3.

Figure 3. The Futility (stopping) Rule When Treating HCV With Boceprevir- or Telaprevir-Included Triple Therapy

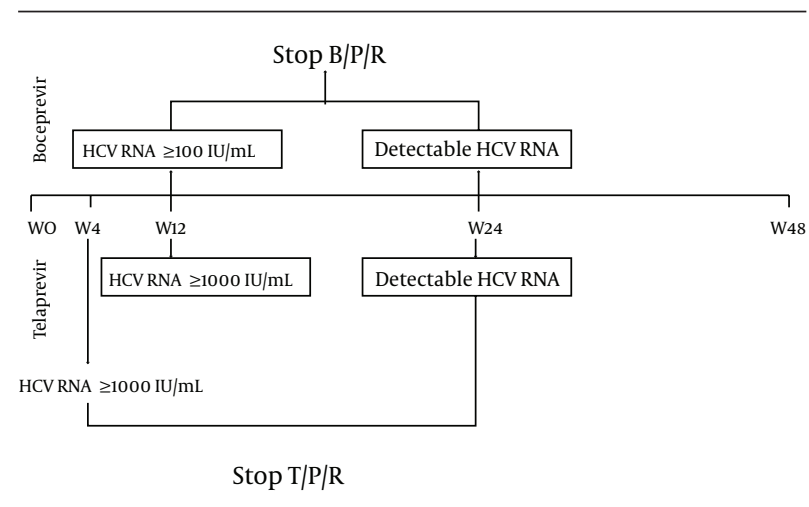

The futility rule which applies to Boceprevir is the HCV RNA $\geq 100 \mathrm{IU} / \mathrm{mL}$ at week 12 or HCV RNA detectable ( $\geq 10-25 \mathrm{IU} / \mathrm{mL}$ ) at week 24 . The similar rule applies to Telaprevir; whereas, HCV RNA $\geq 1000 \mathrm{IU} / \mathrm{mL}$ at week 4 or week 12, and detectable HCV RNA ( $\geq 10-25 \mathrm{IU} / \mathrm{mL}$ ) at week 24 mandate discontinuation of IFN, and hence the triple combination. $\mathrm{B} / \mathrm{P} / \mathrm{R}$ : Boceprevir + PegIFN + RBV, T/P/R: Telaprevir + PegIFN + RBV.

Neither Boceprevir nor Telaprevir should have dose modifications, and if either of the drugs is stopped for any reason it should not be restarted. Using either of these PIs is recommended to strictly follow their summaries of characteristics $(24,25)$.

\subsection{Anticipated Untoward Effects With PIs}

Both Boceprevir and Telaprevir may have potential and life-threatening side effects; thus, health care providers need to be well-informed and trained how to manage these possible adverse events. The most common side effects of Boceprevir in combination with $\mathrm{P} / \mathrm{R}$ include fatigue, anemia, nausea, headache and dysgeusia; whereas, the most common side effects of Telaprevir in combination with $\mathrm{P} / \mathrm{R}$ are rash, with or without pruritus, anorectal burning sensation, and anemia. Telaprevir-induced rash (occurring in almost 35\% of cases) is usually mild; however, it can become severe, and even lead to hospitalization. A recent report has indicated the Telaprevir-included combination therapy-associated anemia to be $37 \%$ vs. $19 \%$ for $\mathrm{P} / \mathrm{R}$. This adverse event is reported to occur in $49 \% \mathrm{vs}$. $29 \%$ of Boceprevir-included combination therapy vs. $\mathrm{P} / \mathrm{R}$, respectively $(24,25,34,35)$.
Noting the benefits and challenges of the currently available PI-included regimens for HCV, well organized trainings are needed to provide practical skills to those who have considered using these regimens for their challenging-to-treat patients. For some specific patients i.e. naïve or treatment-experienced GT1 hepatitis C cases who are strongly willing to be treated with these regimens, patients with high stages of liver fibrosis, and those with comorbidities, the timely management of their HCV with these regimens (rather than waiting for possibly easier regimens in the future) is recommended $(2,12,28)$. In addition, whomever we can treat now is one less patient we need to be worried about in the future.

\section{Local Experience With Protease Inhibitors; the Present Status in Iran}

Following the first consensus meeting held in July 2011, Tehran, Iran, the preliminary agreements on the overall strategies for using PI-included regimens in challengingto-treat hepatitis C patients were made (13). The expert attendees tried to draw a practical image to promote the use and prevent the misuse of these newly available regimens. Based on the agreed upon algorithms during the above consensus meeting (13), field experts started to shortlist their hard-to-treat cases ( mainly GT1 relapsers and nonresponders to the standard $\mathrm{P} / \mathrm{R}$ regimen) to let them through a new promising treatment journey using PIs.

Consideration of these regimens rooted in the unmet needs with $\mathrm{P} / \mathrm{R}$. For instance, the highest success rate ( SVR achievement) using the standard $\mathrm{P} / \mathrm{R}$ regimen in Iranian patients with thalassemia turned to be $51 \%$; therefore, almost a half of these patients have been either nonresponders or relapsers (4).

According to a recent report (5), amongst GT1a-HCV patients (the most prevalent GT in Iran), 50\% achieved SVR, $12 \%$ became nonresponders, $22 \%$ relapsed, and $16 \%$ experienced the breakthrough relapse. In a multivariate analysis, favorable predictive factors for SVR aged 40 or younger upon treatment, non-1a GT, and the baseline HCV RNA level of less than $600,000 \mathrm{IU} / \mathrm{mL}$ (5).

Published evidence has demonstrated an increase in SVR among nonresponders upon triple therapy with Boceprevir (SVR rate of up to 52\%) (8). In relapsers, when Boceprevir is administered after a 4-week lead-in period, the rate of SVR is as high as $69 \%-75 \%$ (8). The lead-in phase allows for the real-time assessment of the patients' response to $\mathrm{P} / \mathrm{R}$ and helps assessment of the likelihood of SVR achievement. Furthermore, lead-in allows RBV to reach a steady state concentration thus may reduce the potential for resistance in patients responsive to $\mathrm{P} / \mathrm{R}$ by decreasing the viral load. It also enables the assessment of patients' adherence and tolerability before adding the $\operatorname{PI}(8,36)$.

Besides, the optimal treatment outcome depends on the virus kinetics. Those patients who demonstrate un- 
detectable HCV RNA at week 4 of the treatment ( following $\mathrm{P} / \mathrm{R}$ ) are more likely to achieve SVR than patients who have undetectable virus by week 12 ( $82 \%-94 \%$ vs. $79 \%$ ) (7).

Evaluation of the liver disease status is recommended before the treatment strategy is defined. With respect to liver fibrosis, when the fibroscan reveals an advanced fibrosis (F3-F4 or F4), even naive GT1 patients may become candidate for a PI-included triple therapy $(37,38)$. However, the clinical decision depends on the lack of contraindications for these regimens, as well as tolerability and affordability $(12,39)$.

There are some characteristic factors which leave an impact on patients' response rate. These include IL28B and core-70 mutation status of the virus. When IL28B genotype is TT and the core-70 mutation is non-Arginine, the decision to start PI-included triple therapy becomes warranted even in naive cases $(11,40)$.

In our local setting, we have started to use Boceprevirincluded triple combination in hard-to-treat $\mathrm{CHC}$ cases over the past 6 months. Some Iranian hepatitis experts have shortlisted almost 40 cases to receive this regimen; however, 23 patients have already been started on therapy and the remaining patients are currently on the waiting list. Due to the lack of an integrated and unified data gathering system (patients are from various centers in different provinces), long term efficacy and safety data of these patients could only be partly contemplated. Fortunately, Iran hepatitis network (IHN) has recently initiated to unifying the evaluation and treatment paradigm in a data registry. This would make contemplation of all patients' clinical, disease-related and treatment data possible under a project entitled "Iran Hepatitis-C Cohort". The infrastructure for this registry has been provided and IHN would proceed to launch this cohort in a few months. Within our collaborative network, we are currently incorporating our patients' baseline characteristics, predictive and prognostic marker profiles, diseaserelated particulars, the so far on-treatment safety, and efficacy data as well as the treatment results in the above database through which an analytical report is expected to be made.

Clinical evidence in global scope has reported that treatment with PIs possibly leads to adverse events in patients with GT1 HCV infection. Anemia is expected to occur in approximately $40-45 \%$ of patients, from whom $40 \%$ tend to require erythropoietin administration (24). This concern has recently been reported to almost identically occur in Telaprevir- and Boceprevir-included treatment of GT1 HCV-infected patients (25). PI-associated anemia can be managed either by erythropoietin administration or RBV dose reduction $(15,36,41)$.

Nevertheless, our recent experience has substantiated that amongst Iranian patients, Boceprevir is well-tolerated and anemia is of less severity. Understanding the reason behind this observation is worth a focused investigation.

\section{Conclusions}

HCV treatment paradigm has dramatically evolved over the past 20 years. This dynamic field has recently offered new hopes for hard-to-treat patients with chronic hepatitis $C$ following the introduction of PIs (Boceprevir and Telaprevir)-included regimens. While $\mathrm{P} / \mathrm{R}$ remains the backbone of HCV therapy, Boceprevir- or Telaprevirincluded triple therapy is being considered as the standard of care for either naive or treatment-experienced GT1 HCV-infected patients. Some emerging anti-HCV therapies are underway. These direct-acting antivirals are expected to provide IFN-free regimens.

The question of why a distinct subset of patients ( especially those who are willing to be treated with the PI-included regimens today, patients with comorbidities, and those with high liver fibrosis level) need to be treated today and waiting for the future therapies is not warranted, was extensively discussed during the present symposium.

Iran Hepatitis Network (IHN) will soon launch the "Iran Hepatitis-C Cohort" to systematically register and follow up with the already enrolled PI-treated patients, and those who would receive either of the PIs from now on. IHN is delighted to welcome collaborations in this project.

\section{Acknowledgements}

Authors would like to thank Drs. P. Dindoust, S.A. Hejazi Farahmand, N. Rahnamay Chitsaz, R. Mostafavi, S. Heidari, H. Rouhani Najafabadi, M. Afarid, M. Eisobky and S. Ibrahim for their organizational/scientific support to this symposium.

\section{Authors' Contribution}

All the authors contributed to all parts of the research; but contribution based on approximate time allocated by each author was as follows; Nasser Ebrahimi Daryani (20\%), Seyed Moayed Alavian (30\%), Mohammad Hossein Somi (20\%), Mohammad Torabi-Nami (30\%).

\section{Financial Disclosure}

The present report outlines the communicated insights during the cross-border HCV symposium held during the 5th International Tehran Hepatitis Congress, May 2013. This symposium received organizational and scientific support from Behestan Darou PJS, Tehran, Iran. Authors declare no conflict of interest upon data review, talk delivery during the meeting, and preparation the report.

\section{Funding/Support}

The study was supported by Baqiyatallah Research Center for Gastroenterology and Liver Diseases, Tehran, Iran. 


\section{References}

1. Manns MP, Wedemeyer H, Cornberg M. Treating viral hepatitis C: efficacy, side effects, and complications. Gut. 2006;55(9):1350-9.

2. Ward JW, Lok AS, Thomas DL, El-Serag HB, Kim WR. Report on a single-topic conference on "Chronic viral hepatitis--strategies to improve effectiveness of screening and treatment". Hepatology. 2012;55(1):307-15.

3. Lok AS, Gardiner DF, Lawitz E, Martorell C, Everson GT, Ghalib R, et al. Preliminary study of two antiviral agents for hepatitis $C$ genotype 1. NEngl J Med. 2012;366(3):216-24.

4. Tabatabaei SV, Alavian SM, Keshvari M, Behnava B, Miri SM, Karimi Elizee P, et al. Low dose ribavirin for treatment of hepatitis $C$ virus infected thalassemia major patients; new indications for combination therapy. Hepat Mon. 2012;12(6):372-81.

5. Namazee N, Sali S, Asadi S, Shafiei M, Behnava B, Alavian SM. Real response to therapy in chronic hepatitis $C$ virus patients: a study from iran. Hepat Mon. 2012;12(9).

6. Alavian SM, Tabatabaei SV, Keshvari M, Behnava B, Miri SM, Elizee PK, et al. Peginterferon alpha-2a and ribavirin treatment of patients with haemophilia and hepatitis $C$ virus infection: a singlecentre study of 367 cases. Liver Int. 2010;30(8):1173-80.

7. Poordad F, McCone JJr, Bacon BR, Bruno S, Manns MP, Sulkowski MS, et al. Boceprevir for untreated chronic HCV genotype 1 infection. N Engl J Med. 2011;364(13):1195-206.

8. Bacon BR, Gordon SC, Lawitz E, Marcellin P, Vierling JM, Zeuzem $\mathrm{S}$, et al. Boceprevir for previously treated chronic HCV genotype 1 infection. N Engl J Med. 2011;364(13):1207-17.

9. Hayashi N, Okanoue T, Tsubouchi H, Toyota J, Chayama K, Kumada H. Efficacy and safety of telaprevir, a new protease inhibitor, for difficult-to-treat patients with genotype 1 chronic hepatitis $C$. J Viral Hepat. 2012;19(2):e134-42.

10. Cunningham M, Foster GR. Efficacy and safety of telaprevir in patients with genotype 1 hepatitis C infection. Therap Adv Gastroenterol. 2012;5(2):139-51.

11. Ghany MG, Nelson DR, Strader DB, Thomas DL, Seeff LB. An update on treatment of genotype 1 chronic hepatitis $C$ virus infection: 2011 practice guideline by the American Association for the Study of Liver Diseases. Hepatology. 2011;54(4):1433-44.

12. European Association for the Study of the Liver . EASL clinical practice guidelines: management of hepatitis $\mathrm{C}$ virus infection.J Hepatol. 2011;55(2):245-64.

13. Alavian SM, Lankarani KB, Aalaei-Andabili SH, Pouryasin A, Ebrahimi Daryani N, Nassiri Toosi M, et al. Treatment of chronic hepatitis C infection: update of the recommendations from scientific leader's meeting-28th July 2011-Tehran, IR Iran. Hepat Mon. 2011;11(9):703-13.

14. Burney T, Dusheiko G. Overview of the PROVE studies evaluating the use of telaprevir in chronic hepatitis $C$ genotype 1 patients. Expert Rev Anti Infect Ther. 2011;9(2):151-60.

15. Imhof I, Simmonds P. Genotype differences in susceptibility and resistance development of hepatitis $C$ virus to protease inhibitors telaprevir (VX-950) and danoprevir (ITMN-191). Hepatology. 2011;53(4):1090-9.

16. Kwo PY, Lawitz EJ, McCone J, Schiff ER, Vierling JM, Pound D, et al. Efficacy of boceprevir, an NS3 protease inhibitor, in combination with peginterferon alfa-2b and ribavirin in treatmentnaive patients with genotype 1 hepatitis C infection (SPRINT-1): an open-label, randomised, multicentre phase 2 trial. Lancet. 2010;376(9742):705-16.

17. Hezode C, Fontaine H, Dorival C, Larrey D, Zoulim F, Canva V, et al. Triple therapy in treatment-experienced patients with hcv-cirrhosis in a multicentre cohort of the french early access programme (anrs co20-cupic) - nct01514890. J hHepatol. 2013;59(3):434-41.

18. Poynard T, Bedossa P, Opolon P. Natural history of liver fibrosis progression in patients with chronic hepatitis $\mathrm{C}$. The OBSVIRC, METAVIR, CLINIVIR, and DOSVIRC groups. Lancet. 1997;349(9055):825-32.

19. Hezode C, Fontaine H, Dorival C, Larrey D, Zoulim F, Canva V, et al. Triple therapy in treatment-experienced patients with HCV-cirrhosis in a multicentre cohort of the French Early Access Programme (ANRS CO20-CUPIC) - NCT01514890. J Hepatol.
2013;59(3):434-41.

20. PegIntron $₫[$ package insert]. Whitehouse Station, NJ: Schering Corporation; 2010.

21. Pegasys $®[$ package insert]. South San Francisco, CA: Genentech, Inc: 2011.

22. Rebetol@[package insert]. Kenilworth, NJ: Schering Corporation; 2003

23. Copegus $囚[$ package insert]. South San Francisco, CA: Genentech, Inc.;2010.

24. Victrelis ${ }^{\mathrm{TM}}$ [package insert]. Whitehouse Station, NJ: Schering Corporation; 2011.

25. Incivek ${ }^{\mathrm{TM}}$ [package insert]. Cambridge, MA: Vertex Pharmaceuticals Incorporated; 2011.

26. Poordad F, Lawitz E, Kowdley KV, Cohen DE, Podsadecki T, Sig gelkow $S$, et al. Exploratory study of oral combination antiviral therapy for hepatitis C. NEngl J Med. 2013;368(1):45-53.

27. Jacobson IM, Gordon SC, Kowdley KV, Yoshida EM, RodriguezTorres M, Sulkowski MS, et al. Sofosbuvir for hepatitis C genotype 2 or 3 in patients without treatment options. $\mathrm{N}$ Engl J Med. 2013;368(20):1867-77.

28. Barreiro P, Vispo E, Poveda E, Fernandez-Montero JV, Soriano V. Hepatitis C therapy: highlights from the 2012 annual meeting of the European Association for the Study of the Liver. Clin Infect Dis. 2013;56(4):560-6.

29. Lawitz E, Mangia A, Wyles D, Rodriguez-Torres M, Hassanein T, Gordon SC, et al. Sofosbuvir for previously untreated chronic hepatitis C infection. N Engl J Med. 2013;368(20):1878-87.

30. Kwong AD, Kauffman RS, Hurter P, Mueller P. Discovery and development of telaprevir: an NS3-4A protease inhibitor for treating genotype 1 chronic hepatitis C virus. Nat Biotechnol. 2011;29(11):993-1003.

31. Venkatraman S. . Discovery of boceprevir, a direct-acting NS3/4A protease inhibitor for treatment of chronic hepatitis $\mathrm{C}$ infections. Trends Pharmacol Sci. 2012;33(5):289-94.

32. Bell TW. Drugs for hepatitis C: unlocking a new mechanism of action. ChemMedChem. 2010;5(10):1663-5.

33. Fried MW, Hadziyannis SJ, Shiffman ML, Messinger D, Zeuzem S Rapid virological response is the most important predictor of sustained virological response across genotypes in patients with chronic hepatitis C virus infection. J Hepatol. 2011;55(1):69-75.

34. Yamada I, Suzuki F, Kamiya N, Aoki K, Sakurai Y, Kano M, et al. Safety, pharmacokinetics and resistant variants of telaprevir alone for 12 weeks in hepatitis $\mathrm{C}$ virus genotype $1 \mathrm{~b}$ infection. J Viral Hepat. 2012;19(2):e112-9.

35. Vera-Llonch M, Martin M, Aggarwal J, Donepudi M, Bayliss M Goss T, et al. Health-related quality of life in genotype 1 treatment-naive chronic hepatitis $\mathrm{C}$ patients receiving telaprevir combination treatment in the ADVANCE study. Aliment Pharmacol Ther. 2013

36. Alavian SM, Lankarani KB, Aalaei-Andabili SH, Pouryasin A, Ebrahimi Daryani N, Nassiri Toosi M, et al . Treatment of Chronic Hepatitis C Infection: Update of the Recommendations from Scientific Leader's Meeting-28th July 2011-Tehran, IR Iran. Hepat Mon. 2011;11(9):703-13.

37. Telaprevir (Incivek) and boceprevir(Victrelis) for chronic hepatitis C. Med Lett Drugs Ther. 2011;53(1369):57-9.

38. Petta S, Craxi A. How to optimize HCV therapy in genotype 1 patients: predictors of response. Liver Int. 2013;33 Suppl 1:23-9.

39. Bourlière $\mathrm{M}$, Wendt $\mathrm{A}$, Fontaine $\mathrm{H}$, Hézode $\mathrm{C}$, Pol $\mathrm{S}$, Bronowicki JP. How to optimize HCV therapy in genotype 1 patients with cirrhosis. Liver Int. 2013;33(1):46-55.

40. Camma C, Petta S, Enea M, Bruno R, Bronte F, Capursi V, et al. Costeffectiveness of boceprevir or telaprevir for untreated patients with genotype 1 chronic hepatitis C. Hepatology. 2012;56(3):85060 .

41. Kurosaki M, Tanaka Y, Nishida N, Sakamoto N, Enomoto N, Honda M, Sugiyama M, Matsuura K, Sugauchi F, Asahina Y, Nakagawa M, Watanabe M, Sakamoto M, Maekawa S, Sakai A, Kaneko S, Ito K, Masaki N, Tokunaga K, Izumi N, Mizokami M. Pre-treatment prediction of response to pegylated-interferon plus ribavirin for chronic hepatitis C using genetic polymorphism in IL28B and viral factors. J Hepatol. 2011;54(3):439-48. 